\title{
Monitoring of the Migratory Ability of Heavy Metals in the Soil-Plant System
}

\author{
Ekaterina Gorshenina $^{1}$ (D), Alina Baitelova ${ }^{1}$ (D), Natalia Rakhimova ${ }^{1}$ (D) Ludmila Bykova $^{1}$ (iD), Ekaterina \\ Savchenkova 1 (iD
}

1 Federal State Budgetary Educational Institution of Higher Education “Orenburg State University”, Russia

* Correspondence: bykovaludmi1a@yandex.ru;

Scopus Author ID 55945057500

Received: 30.09.2020; Revised: 20.10.2020; Accepted: 22.10.2020; Published: 25.10.2020

\begin{abstract}
The profile migration of pollutants that occurs most intensively in spring, autumn, and summer with a large amount of precipitation when intensive descending flows of soil moisture take place is of particular importance. The migration of heavy metals is limited by their deposition on geochemical barriers. The study of the profile migration and accumulation of heavy metals showed that metals have an unequal behavior in soils; a change in their content in the profile is noted. The article presents the dynamics of the distribution of moving forms of heavy metals in different soils of the Orenburg region. An equation of exponential regression was proposed. The equation allows assessing the migrative ability of heavy metal by the value of indicator $\alpha$. There were studied physical and chemical characteristics of the soil, namely its composition, the content of heavy metals, which in total affects the overall state of the soil and plant system. The structure of the system was analyzed and determined by probabilities of the presence of a pollutant in the components of the system. As a result, a complex indicator showing the movement of heavy metals in the soil-plant system was calculated.
\end{abstract}

Keywords: physical and chemical features of the soil; heavy metals; soil composition; the state of the soil-plant system.

(C) 2020 by the authors. This article is an open-access article distributed under the terms and conditions of the Creative Commons Attribution (CC BY) license (https://creativecommons.org/licenses/by/4.0/).

\section{Introduction}

Recent studies of physical and chemical characteristics of soils have led to an increase in the number of significant research materials on the content of heavy metals (HM), pesticides, and biogenic and other substances in soils. Predicting transformations of the qualitative composition of soil and the presence of toxic compounds in it are very relevant and complex tasks; even mathematical modeling methods are used to solve it. In addition to mathematical models based on experimental data (regression models) that do not allow identifying the mechanisms arising in the system, simulation modeling finds its application. These models typically utilize many components that take into account the processes of modification of chemical compounds, diffusion, sorption, and others. Simulation modeling provides an opportunity to integrate a large amount of information about the physical and chemical processes carried out in the system, which allows detailed analysis and prediction of dynamic characteristics. However, studying such large and complex models bring grave mathematical difficulties. It should be emphasized that, for a comprehensive understanding of the system, it is enough to limit to one-, two-, or three-component models, which are much easier to analyze 
and, at the same time, provide an opportunity to correctly assess the fundamental characteristics of the system's behavior [1].

\section{Materials and Methods}

The examined area was an object of the choice of sites with homogeneous soil and vegetation cover in accordance with the methods given below. A mixed soil sample consisting of 5 point samples taken by the envelope method was selected from a chosen site. Samples were selected with a shovel to the depth of the arable layer $(30 \mathrm{~cm})$ on arable land and with a soil sampler to a depth of $0-5 \mathrm{~cm} ; 5-10 \mathrm{~cm} ; 10-20 \mathrm{~cm} ; 20-30 \mathrm{~cm} ; 30-40 \mathrm{~cm} ; 40-50 \mathrm{~cm}$ on virgin soil.

Each point sample was thoroughly mixed and taken to a clean polyethylene container to create a mixed sample. All the individual samples provided a mixed sample with approximately the same amount of soil. All five samples were mixed together, cleaned from stones, roots, and other inclusions, and thoroughly stirred. About $1 \mathrm{~kg}$ of soil was selected from the total mass by the quartation method, which was subsequently analyzed.

The resulting soil samples were brought to an air-dry state, and all large lumps were crushed. Then a sample weighing $200 \mathrm{~g}$ was selected by quartation and sifted through a Capron sieve with $1 \mathrm{~mm}$ holes.

Plant samples were selected at the same sites as soil samples. To obtain a combined sample, plants weighing $0.5-1 \mathrm{~kg}$ with natural moisture were selected from 10 point samples ("Methodical guidelines for the definition of heavy metals in the soils of agricultural land and crop production.”, Moscow, 1992, Central Research Institute for Agrichemical Services of Agriculture).

The ground part of the grass cover was cut with a sharp knife not clogging with the soil, then laid in a polyethylene film with a label. If the lower part of the plant was contaminated with the soil, the plants were cut $3-5 \mathrm{~cm}$ above the soil surface.

Samples of grass and green mass of crops were conducted by GOST 27262-87 "Vegetable feeds. Sampling methods." Herbs from pastures or hayfields were selected on the allocated 10 accounting sites of the size of $1 \mathrm{~m}^{2}$, placing them on the diagonals of the site. The herbage was cut off at an altitude of $3-5 \mathrm{~cm}$.

Selected point samples of green mass were collected on a tarp, carefully mixed, and spread out as an even layer receiving a combined sample. The average sample for analysis was selected from the combined green mass sample. To compile the average sample that weighs $1.5-2 \mathrm{~kg}$, the grass was taken in portions of 150-200 grams from 10 different sites.

The combined samples of the plant material were shredded into segments of $1-3 \mathrm{~cm}$. Then, the average sample was allocated by quartation; the mass of the latter after drying was $100 \mathrm{~g}$. Samples were dried in a drying cabinet at $\mathrm{T}=600 \mathrm{C}$ to the air-dried condition (GOST 27548-87 "Vegetable feeds. Methods for determination of moisture"). The air-dried sample was crushed at the mill and sifted through a sieve with a hole diameter of $2 \mathrm{~mm}$. The residue on the sieve after grinding was added to the sifted part and thoroughly stirred. The prepared samples were stored in a glass jar with a ground stopper in a dry place; the samples were later used for analysis. 


\section{Results and Discussion}

We will analyze the system that consists of the following components: soil, the root system of plants, and their above-ground part. Such a system refers to the self-regulating ones that were formed in the course of evolution as a system as a whole, and each of its parts interrelated.

Energy and substance are transferred during the interconnection of the elements of the system. The original requirements will be determined as follows:

1) at the initial point, the concentration of a pollutant $\mathrm{C} 0$ is introduced into the system (for example, through the atmosphere);

2) there takes place a substance exchange between each element of the system with different intensity:

$\lambda_{1}$ - the intensity of the movement of substances from the soil to the roots of plants;

$\lambda_{2}$ - the intensity of the movement of substances from the roots of plants to their above-ground part;

$\lambda_{3}$ - the intensity of the movement of substances from the above-ground part of the plant to the soil.

The structure of the system will be established by the probabilities $(\mathrm{P})$ of the presence of a pollutant (POL) in the components of the system: $\mathrm{P}_{\Pi}$ - the probability of the presence of POL in the soil, $\mathrm{P}_{\mathrm{K}}$ - the probability of the presence of POL in the root system of plants, $\mathrm{P}_{\mathrm{H}}$ the probability of detection of POL in the above-ground part of plants. Let's set a task: to calculate the concentration of POL in each of the elements of the system, providing intensional stationarity of the switch of the pollutant from one element to another while the time of control tends to infinity [2].

A single stream of events that takes the system out of the $P_{п}$ state will flow with an intensity $\lambda_{1}$. The probability that the system will come out of the $P_{\text {п }}$ state in the time $\Delta t$ will be equal to:

$$
\lambda_{1} \cdot \Delta t
$$

and the probability that it will not:

$$
\left(1-\lambda_{1} \cdot \Delta t\right)
$$

The total probability will be:

$$
P_{\text {п }}(t+\Delta t)=P_{\text {п }}(t)\left(1-\lambda_{1} \cdot \Delta t\right)+\lambda_{3} P_{\mathrm{H}}(t) \Delta t .
$$

After reduction:

$$
P_{n}(t+\Delta t)-P_{n}(t)=-P_{n}(t) \lambda \Delta t+\lambda_{3} P_{H}(t) \Delta t
$$

With $\Delta \mathrm{t} \rightarrow 0$ :

$$
\frac{d P_{i^{\prime}}(t)}{d t}=-P_{i^{\prime}}(t) \lambda_{1}+\lambda_{3} P_{i}(t)
$$

In the same way, equations for the states of the systems of $\mathrm{P \kappa}_{\mathrm{r}}(\mathrm{t})$ and $\mathrm{PH}_{\mathrm{H}}(\mathrm{t})$ can be made:

$$
\begin{aligned}
& \frac{d P_{\mathrm{K}}(t)}{d t}=-\lambda_{2} P_{\mathrm{K}}(t)+\lambda_{1} P_{\mathrm{\Pi}}(t) \\
& \frac{d P_{\mathrm{H}}(t)}{d t}=-\lambda_{3} P_{\mathrm{H}}+\lambda_{2} P_{\mathrm{K}}
\end{aligned}
$$

Equations 1, 2, and 3 together create a system of Kolmogorov equations where the probabilities of Рп, Рк, and $\mathrm{PH}_{\mathrm{H}}$ appear as unknown values. As noted above, they can be interpreted as the probability of POL detection in the roots, above-ground part of plants, and 
soil. Different processes, such as diffusion, sorption, dry and wet deposition, etc., are responsible for moving pollution from one environment to another. If the processes take place in a large amount of time $(\mathrm{t} \rightarrow \infty)$, then the components of the system are diagnosed with concentrations of POL according to the probabilities of Рп, Рк, and $\mathrm{PH}_{\mathrm{H}}$

The final probabilities do not depend on time due to following the reasons, therefore:

$$
\frac{d P_{i^{\prime}}}{d t}=0 ; \frac{d P_{e}}{d t}=0 ; \frac{d P_{i}}{d t}=0 \text {. }
$$

Then:

$$
\left\{\begin{array}{l}
-\lambda_{1} P_{\mathrm{p}}+\lambda_{3} P_{\mathrm{H}}=0 \\
\lambda_{2} P_{\mathrm{K}}+\lambda_{1} P_{\mathrm{I}}=0 \\
-\lambda_{3} P_{\mathrm{H}}+\lambda_{2} P_{\mathrm{K}}=0
\end{array}\right.
$$

The system (4) is over-determined, so we will remove the third equation and substitute instead: $P_{\mathrm{\Pi}}+P_{\mathrm{K}}+P_{\mathrm{H}}=1$.

Then:

$$
\left\{\begin{array}{l}
-\lambda_{1} P_{i^{\prime}}+\lambda_{3} P_{i}=0 \\
-\lambda_{2} P_{e}+\lambda_{1} P_{i^{\prime}}=0 \\
P_{A}=1-P_{e}-P_{i}
\end{array}\right.
$$

Switching from probabilities to concentrations:

$$
\left\{\begin{array}{l}
-\lambda_{1} C_{\Pi}+\lambda_{3} C_{\mathrm{H}}=0 \\
-\lambda_{2} C_{\mathrm{K}}+\lambda_{1} C_{\mathrm{\Pi}^{\prime}}=0 \\
C_{\Pi}=C_{\mathrm{o}}-C_{\mathrm{K}}-C_{\mathrm{H}}
\end{array}\right.
$$

Solving the system (6), we have:

$$
C_{\mathrm{H}}=\frac{\lambda_{1} \lambda_{2} C_{\mathrm{o}}}{\lambda_{1} \lambda_{2}+\lambda_{2} \lambda_{3}+\lambda_{3} \lambda_{1}} ; \quad C_{\mathrm{\kappa}}=\frac{\lambda_{1} \lambda_{3} C_{\mathrm{o}}}{\lambda_{1} \lambda_{2}+\lambda_{2} \lambda_{3}+\lambda_{3} \lambda_{1}} ; \quad C_{\text {п }}=\frac{\lambda_{2} \lambda_{3} C_{\mathrm{o}}}{\lambda_{1} \lambda_{2}+\lambda_{2} \lambda_{3}+\lambda_{3} \lambda_{1}}
$$

The developed dependencies allow determining the preferential distribution of substances in subsystems by the known intensity of the transitions of substances in the soilplant system. But it is worth emphasizing that the intensity of transitions is established by the characteristics of soils and plants.

For the integral estimate of soil and plant complexes, a combined indicator is recommended taking into account the physical and chemical features of soils and plants. A denominator in equations (7) is proposed as such a criterion. Tables 1 and 2 (fragments) show calculated differential indicators that give an idea of the migratory properties of metals in soil and plant systems. When studying the tables, it should be pointed out that the differential indicator I demonstrate the degree of distribution of heavy metals in soil-plant systems. Thus, if $\mathrm{I}=3$, it indicates an even distribution of heavy metals in the soil elements, roots, and the above-ground part of the plant [3].

The closer to three $I$ is, the more even the distribution of HM is in the soil-plant system.

An analysis of tables shows an even distribution in the studied soil-plant systems for zinc, cadmium, cobalt, nickel, and mercury. Metals such as copper, manganese, nickel, and chromium feature with a significantly heterogeneous distribution in these systems [4]. 
Table 1. The differential indicator of soil-plant contamination with copper (fragment).

\begin{tabular}{l|l|l|l|l|l|l|l} 
Point of sample selection & Tansy & Wild oats & Bluegrass & Milfoil & Brome & Bush grass & Dandelion \\
\hline 1.1 & 18.32 & 17.35 & 32.04 & 13.85 & 15.4 & 30.42 & 20.62 \\
\hline 1.2 & 13.73 & 23.68 & 18.73 & 77.48 & 22.46 & 30.71 & 10.33 \\
\hline 1.3 & 11.04 & 53.83 & 32.76 & 19.07 & 25.64 & 21.15 & 37.06 \\
\hline 1.4 & 68.80 & 47.68 & 28.1 & 90.39 & 20.41 & 46.48 & 34.54 \\
\hline 1.5 & 21.17 & 61.87 & 16.35 & 47.51 & 47.36 & 34.63 & 18.40 \\
\hline 1.6 & 12.71 & 24.24 & 37.5 & 69.6 & 28.15 & 32.58 & 24.30 \\
\hline 1.7 & 18.35 & 28.74 & 37.16 & 16.56 & 15.77 & 12.16 & 38.6 \\
\hline 2.1 & 11.37 & 21.76 & 30.8 & 48.63 & 39.95 & 35.46 & 38.21 \\
\hline 2.2 & 26.48 & 41.03 & 12.87 & 62.86 & 51.79 & 17.28 & 31.76 \\
\hline 2.3 & 7.70 & 12.75 & 46.92 & 32.76 & 29.46 & 16.76 & 23.73 \\
\hline 2.4 & 33.48 & 20.77 & 40.62 & 41.11 & 20.15 & 18.83 & 19.22 \\
\hline 2.5 & 9.2 & 48.71 & 41.88 & 17.02 & 58.62 & 16.24 & 22.17 \\
\hline 2.6 & 14.68 & 16.75 & 43.15 & 75.95 & 26.34 & 14.02 & 39.26 \\
\hline 2.7 & 31.52 & 25.75 & 48.95 & 39.05 & 43.92 & 22.1 & 28.19 \\
\hline 3.1 & 11.17 & 23.22 & 24.43 & 26.3 & 58.64 & 26.46 & 22.26 \\
\hline 3.2 & 8.18 & 42.71 & 37.86 & 93.01 & 15.75 & 46.57 & 47.37
\end{tabular}

Table 2. The differential indicator of soil-plant contamination with zinc (fragment).

\begin{tabular}{c|c|c|c|c|c|c|c}
$\begin{array}{c}\text { Point of sample } \\
\text { selection }\end{array}$ & Tansy & $\begin{array}{c}\text { Wild } \\
\text { oats }\end{array}$ & Bluegrass & Milfoil & Brome & $\begin{array}{c}\text { Bush } \\
\text { grass }\end{array}$ & Dandelion \\
\hline 1.1 & 7.48 & 6.16 & 9.87 & 7.05 & 4.38 & 7.2 & 8.06 \\
\hline 1.2 & 9.25 & 5.03 & 2.95 & 6.11 & 11.65 & 4.98 & 4.07 \\
\hline 1.3 & 8.32 & 6.26 & 5.83 & 6.82 & 5.46 & 8.85 & 3.98 \\
\hline 1.4 & 5.16 & 9.30 & 5.8 & 5.31 & 7.66 & 8.05 & 6.69 \\
\hline 1.5 & 11.44 & 5.88 & 10.42 & 11.01 & 10.63 & 6.62 & 4.84 \\
\hline 1.6 & 7.05 & 7.08 & 4.21 & 5.04 & 1.07 & 3.97 & 11.67 \\
\hline 1.7 & 13.45 & 6.08 & 3.84 & 12.34 & 5.47 & 7.93 & 6.04 \\
\hline 2.1 & 8.97 & 4.63 & 4.59 & 8.98 & 7.52 & 5.85 & 7.43 \\
\hline 2.2 & 5.49 & 7.6 & 4.49 & 5.88 & 5.22 & 4.88 & 0.82 \\
\hline 2.3 & 9.72 & 7.79 & 4.65 & 5.41 & 4.88 & 10.96 & 5.86 \\
\hline 2.4 & 5.57 & 6.28 & 3.6 & 7.27 & 9.21 & 8.61 & 7.55 \\
\hline 2.5 & 6.79 & 4.63 & 3.57 & 8.84 & 9.52 & 4.34 & 5.77 \\
\hline 2.6 & 5.08 & 11.1 & 3.04 & 8.41 & 5.16 & 7.66 & 7.69 \\
\hline 2.7 & 7.42 & 5.15 & 5.03 & 4.8 & 2.97 & 7.34 & 6.15 \\
\hline 3.1 & 8.79 & 7.35 & 3.54 & 10.45 & 4.15 & 6.25 & 6.59 \\
\hline 3.2 & 8.86 & 10.68 & 7.1 & 5.87 & 7.37 & 7.82 & 4.33
\end{tabular}

The results of the calculation of a complex indicator showing the movement of HM in soil-plant systems are presented in Table 3. The calculation was made for each metal, and then there was computed a root-mean-square value for each soil-plant system. The formula:

$$
\text { Int }=\sqrt{\sum_{n=i} I_{i}^{2}} / N
$$

where $I$ is a differential indicator for metal $i$;

$\mathrm{N}$ is a number of items (HM) that are summed up.

The first column of the table presents the soil sampling points. The "+" means a plant is growing on this soil (e.g., 1.1 + Tansy indicates that Tansy grows on the soil).

We studied 9 elements, and the lowest value the complex Int indicator can reach is 9. It means that all the studied metals are evenly distributed among the components of the soilplant system. The higher the Int is, the more heterogeneous the distribution of metals between the root system of plants and their above-ground part is. Soil-plant systems with a complex indicator of more than 100 are shown in Table 3 [5].

Table 3. Complex indicator (fragment).

\begin{tabular}{c|c|c|c|c|c|c|c}
$\begin{array}{c}\text { Point of sample } \\
\text { selection }\end{array}$ & +Tansy & $\begin{array}{c}+ \text { Wild } \\
\text { oats }\end{array}$ & +Bluegrass & +Milfoil & +Brome & +Bush grass & +Dandelion \\
\hline 1.1 & 39 & 28.1 & 49.3 & 71.8 & 38.6 & 50.7 & 31.2 \\
\hline 1.2 & 174.2 & 29 & 58.2 & 82.5 & 32.2 & 37.6 & 28 \\
\hline 1.3 & 369.4 & 73.8 & 73 & 38.2 & 35.4 & 92.9 & 88.2 \\
\hline 1.4 & 71.6 & 57.4 & 37.8 & 95.3 & 182.8 & 60.8 & 48.2 \\
\hline \\
https://biointerfaceresearch.com/
\end{tabular}




\begin{tabular}{c|c|c|c|c|c|c|c}
$\begin{array}{c}\text { Point of sample } \\
\text { selection }\end{array}$ & +Tansy & $\begin{array}{c}\text { +Wild } \\
\text { oats }\end{array}$ & +Bluegrass & +Milfoil & +Brome & +Bush grass & +Dandelion \\
\hline 1.5 & 41.4 & 65.1 & 34.4 & 66.9 & 67.8 & 48 & 38.4 \\
\hline 1.6 & 21.5 & 32.7 & 42.3 & 79.6 & 37.5 & 36.2 & 32.8 \\
\hline 1.7 & 29.3 & 42.3 & 79.8 & 36.7 & 31.8 & 40.3 & 47 \\
\hline 2.1 & 24.5 & 36.3 & 97.5 & 54.2 & 45.9 & 43.7 & 53.4 \\
\hline 2.2 & 30.3 & 58.7 & 31.4 & 74.1 & 62.3 & 43.9 & 54.3 \\
\hline 2.3 & 25.9 & 41.2 & 53.3 & 187.8 & 182.2 & 34 & 53.1 \\
\hline 2.4 & 45.7 & 52.9 & 81 & 45.2 & 29.2 & 36.2 & 175.6 \\
\hline 2.5 & 61.4 & 212.1 & 54.5 & 31.9 & 63 & 28.8 & 41.2 \\
\hline 2.6 & 24.3 & 35.4 & 76.5 & 82.6 & 29.4 & 83.1 & 124.7 \\
\hline 2.7 & 40.2 & 46.6 & 62.7 & 71.8 & 57.5 & 98.7 & 43.1 \\
\hline 3.1 & 22.7 & 42.9 & 35.3 & 45.6 & 71.6 & 40.6 & 40.4 \\
\hline 3.2 & 30 & 51 & 41.9 & 97.7 & 39.1 & 83.7 & 51.9
\end{tabular}

\section{Conclusions}

On the basis of the proposed mathematical model and conducted analytical studies, we calculated the risks of heavy metal contamination of soil, above-ground, and root systems of plants. The proposed differential and integral indicators adequately characterize the distribution of a particular metal in the soil-plant system and the general distribution of all heavy metals in a particular soil-plant system.

\section{Funding}

This research received no external funding.

\section{Acknowledgments}

This research has no acknowledgment.

\section{Conflicts of Interest}

The funders had no role in the design of the study; in the collection, analyses, or interpretation of data; in the writing of the manuscript, or in the decision to publish the results.

\section{References}

1. Enya, O.; Lin, C.; Qin, J. Heavy metal contamination status in soil-plant system in the Upper Mersey Estuarine Floodplain, Northwest England. Mar Pollut Bull. 2019, 146, 292-304, https://doi.org/10.1016/j.marpolbul.2019.06.026.

2. Andráš, P.; Matos, J.X.; Turisová, I.; Batista, M.J.; Kanianska, R.; Kharbish, S. The interaction of heavy metals and metalloids in the soil-plant system in the São Domingos mining area (Iberian Pyrite Belt, Portugal). Environ Sci Pollut Res Int. 2018, 25, 20615-20630, https://doi.org/10.1007/s11356-018-2205-x.

3. Wang, Z.; Qin, H.; Wang, J. Accumulation of uranium and heavy metals in the soil-plant system in Xiazhuang uranium ore field, Guangdong Province, China. Environ Geochem Health. 2019, 41, 2413-242,. https://doi.org/10.1007/s10653-019-00286-7.

4. Wiche, O.; Székely, B.; Moschner, C.; Heilmeier, H. Germanium in the soil-plant system-a review. Environ Sci Pollut Res Int. 2018, 25, 31938-31956, https://doi.org/10.1007/s11356-018-3172-y.

5. Chen, J.Y.; Liu, G.B.; Cui, J.L.; Xiao, T.F. Mobilization of Heavy Metals in a Soil-Plant System and Risk Assessment in the Dabaoshan Mine Area, Guangdong Province, China. Huan Jing Ke Xue. 2019, 40, 56295639, https://doi.org/10.13227/j.hjkx.201906229.

6. El Azhari, A.; Rhoujjati, A.; El Hachimi. M.L.; Ambrosi, J.P. Pollution and ecological risk assessment of heavy metals in the soil-plant system and the sediment-water column around a former $\mathrm{Pb} / \mathrm{Zn}$-mining area in NE Morocco. Ecotoxicol Environ Saf. 2017, 144, 464-474, https://doi.org/10.1016/j.ecoenv.2017.06.051.

7. Li, X.; Cai, Y.; Liu, D.; Ai, Y.; Zhang, M.; Gao, Y.; Zhang, Y.; Zhang, X.; Yan, X.; Liu, B.; Yu, H.; Mielke, H. W. Occurrence, fate, and transport of potentially toxic metals (PTMs) in an alkaline rhizosphere soilplant (Maize, Zea mays L.) system: the role of Bacillus subtilis. Environ Sci Pollut Res Int. 2019, 26, 55645576, https://doi.org/10.1007/s11356-018-4031-6. 
8. Fang, A.; Dong, J.; Zhang, R. Simulation of Heavy Metals Migration in Soil-Wheat System of Mining Area. Int J Environ Res Public Health 2019, 16, https://doi.org/10.3390/ijerph16142550.

9. Chen. F.; Zeng, S.; Ma, J.; Li, X.; Zhang, S.; Zhu, Q. Interactions between decabromodiphenyl ether and lead in soil-plant system. Chemosphere 2019, 236, https://doi.org/10.1016/j.chemosphere.2019.124406.

10. Fan, Y.; Li, Y.; Li, H.; Cheng, F. Evaluating heavy metal accumulation and potential risks in soil-plant systems applied with magnesium slag-based fertilizer. Chemosphere 2018, 197, 382-388, https://doi.org/10.1016/j.chemosphere.2018.01.055.

11. Gabarrón, M.; Faz, A.; Martínez-Martínez, S.; Acosta, J.A. Change in metals and arsenic distribution in soil and their bioavailability beside old tailing ponds. J Environ Manage 2018, 212, 292-300, https://doi.org/10.1016/j.jenvman.2018.02.010.

12. Le, T.T.; Yoon, H.; Son, M.H.; Kang, Y.G.; Chang, Y.S. Treatability of hexabromocyclododecane using $\mathrm{Pd} / \mathrm{Fe}$ nanoparticles in the soil-plant system: Effects of humic acids. Sci Total Environ. 2019, 689, 444-450, https://doi.org/10.1016/j.scitotenv.2019.06.290.

13. Gorshenina, E.L.; Rakhimova, N.N. Distribution of moving forms of heavy metals in the soils of Orenburg region. In: Proceedings of the scientific conference on problems of geoecology, engineering geology, and hydrogeology. Tomsk, Russia, 2010; Tomsk, Russia, 2010; pp. 111-1114.

14. Yuan, H.; Song, S.; An, S.; Liu, E. Ecological risk assessment of potentially toxic elements (PTEs) in the soil-plant system after reclamation of dredged sediment. Environ Sci Pollut Res Int. 2018, 25, 29181-29191, https://doi.org/10.1007/s11356-018-2950-X.

15. Luo, X.; Bing, H.; Luo, Z.; Wang, Y.; Jin, L. Impacts of atmospheric particulate matter pollution on environmental biogeochemistry of trace metals in soil-plant system: A review. Environ Pollut. 2019, 255, https://doi.org/10.1016/j.envpol.2019.113138.

16. Gu, C.; Bai, Y. Heavy metal leaching and plant uptake in mudflat soils amended with sewage sludge. Environ Sci Pollut Res Int. 2018, 25, 31031-31039, https://doi.org/10.1007/s11356-018-3089-5.

17. Efremov, I.V.; Gorshenina, E.L.; Puyto, L.V. Assessment of the dynamics of heavy metal concentration by soil profile. In: Proceedings of the All-Russian Scientific and Methodical Conference with international participation "University Complex as a regional center of education, science, and culture.", Orenburg, Russia; Orenburg State University: Orenburg, Russia, 2017; pp. 125-128.

18. Zhang, Y.; Yin, C.; Cao, S.; Cheng, L.; Wu, G.; Guo, J. Heavy metal accumulation and health risk assessment in soil-wheat system under different nitrogen levels. Sci Total Environ. 2018, 622-623, 1499-1508, https://doi.org/10.1016/j.scitotenv.2017.09.317.

19. Efremov, I.V.; Gorshenina, E.L.; Savchenkova, E.E.; Chernova O.N.; Litvinov V.A. Integral characteristic of heavy metal migration in the biogeocenes of the Southern Urals. Science and education: fundamentals, technologies, innovations. Proceedings of the International Scientific Conference dedicated to the 60th anniversary of Orenburg State University, Orenburg, Russia, 15-17 September 2015; Universitet: Orenburg, Russia, 2015; pp. 113-116.

20. Efremov, I.V.; Gorshenina, E.L.; Solopova, V.A.; Rakhimova, N.N.; Ryabykh, E.I.; Chernova O.N. Comprehensive assessment of the migration capacity and the risk of heavy metal contamination of soil and plant system components. Vestnik of OSU 2019, 13, 133-137.

21. Parada, J.; Rubilar, O.; Sousa, D.Z.; Martínez, M.; Fernández-Baldo, M.A.; Tortella, G.R. Short term changes in the abundance of nitrifying microorganisms in a soil-plant system simultaneously exposed to copper nanoparticles and atrazine. Sci Total Environ. 2019, 670, 1068-1074, https://doi.org/10.1016/j.scitotenv.2019.03.221.

22. Efremov, I.V.; Solopova, V.A.; Gorshenina, E.L.; Rakhimova, N.N.; Eremina, N.V.; Savchenkova, E.E.; Litvinov, V.A.; Chekmareva, O.V. Orenburg Region soil and vegetation complex pollution risk evaluation. International Journal of Green Pharmacy 2018, 11, http://dx.doi.org/10.22377/ijgp.v11i03.1162.

23. Al Souki, K.S.; Liné, C.; Louvel, B.; Waterlot, C.; Douay, F.; Pourrut, B. Miscanthus x giganteus culture on soils highly contaminated by metals: Modelling leaf decomposition impact on metal mobility and bioavailability in the soil-plant system. Ecotoxicol Environ Saf. 2020, 199, https://doi.org/10.1016/j.ecoenv.2020.110654.

24. Aladesanmi, O.T.; Oroboade, J.G.; Osisiogu, C.P.; Osewole, A.O. Bioaccumulation Factor of Selected Heavy Metals in Zea mays. J Health Pollut. 2019, 9.

25. Imseng, M.; Wiggenhauser, M.; Müller, M.; Keller, A.; Frossard, E.; Wilcke, W.; Bigalke, M. The Fate of Zn in Agricultural Soils: A Stable Isotope Approach to Anthropogenic Impact, Soil Formation, and SoilPlant Cycling. Environ Sci Technol. 2019, 53, 4140-4149, https://doi.org/10.1021/acs.est.8b03675.

26. Zahedifar, M.; Moosavi, A.A.; Zarei, Z.; Shafigh, M.; Karimian, F. Heavy metals content and distribution in basil (Ocimum basilicum L.) as influenced by cadmium and different potassium sources. Int $J$ Phytoremediation 2019, 21, 435-447, https://doi.org/10.1080/15226514.2018.1537253. 